\title{
RELAÇÕES DE GÊNERO E VIOLÊNCIA CONTRA A MULHER NA MICRORREGIÃO BICO DO PAPAGAIO/TO: CONTRIBUIÇÕES DO CENTRO DE REFERÊNCIA EM CIDADANIA E DIREITOS HUMANOS
}

\section{GENDER RELATIONS AND VIOLENCE AGAINST WOMEN IN THE MICRO-REGION OF BICO DO PAPAGAIO / TO: THE CONTRIBUTIONS FROM THE REFERENCE CENTER FOR CITIZENSHIP AND HUMAN RIGHTS}

\author{
Karina Almeida de Sousa* \\ ORCID: https://orcid.org/0000-0002-2552-2046 \\ Liza Aparecida Brasílio** \\ ORCID: https://orcid.org/0000-0003-4442-1205
}

\section{Resumo}

Cidadania, direitos humanos e diversidade são debates urgentes em sociedades que buscam consolidar avanços democráticos. Os direitos humanos e a cidadania são históricos, portanto, contextuais. Conseguinte, a disseminação dos direitos de cidadania a partir do reconhecimento dos direitos políticos, sociais, civis e culturais é interdependente das múltiplas configurações sociais. Foram as perspectivas supracitadas que orientaram a implementação de um "Centro de Referência em Cidadania e Direitos Humanos", na microrregião do Bico do Papagaio, extremo norte do estado do Tocantins. A região, marcada pela diversidade étnica e racial, também apresenta elevados índices de vulnerabilidade social, o que nos permite propor algumas reflexões sobre o papel das instituições públicas enquanto propulsoras da promoção da cidadania e dos direitos humanos, no caso específico no que toca à garantia e aos avanços relacionados ao gênero e ao combate à violência contra a mulher.

Palavras-chave: Cidadania; Direitos humanos; Extensão universitária; Gênero; Violência contra a mulher.

Data recebimento: $23 / 09 / 2020$

Data de aceite: $11 / 06 / 2021$

\begin{abstract}
Citizenship, human rights and diversity are subjects of urgent debates in societies seeking to consolidate democratic advances. Human rights and citizenship are historical, therefore, contextual. Consequently, the dissemination of citizenship rights based on the recognition of political, social, civil and cultural rights is interdependent on multiple social configurations. It was the aforementioned perspectives that guided the implementation of the "Reference Center for Citizenship and Human Rights", in the micro-region of Bico do Papagaio, in the extreme north of the state of Tocantins. The region, marked by ethnic and racial diversity, also presents high levels of social vulnerability, which allows us some reflections on the role of public institutions as promoters of citizenship and human rights, specifically regarding the guarantee and advances related to gender and combating violence against women.
\end{abstract}

Keywords: Citizenship; Human rights; University extension; Gender; Violence against women.

* Professora da Universidade Federal do Norte do Tocantins (UFNT), Tocantinópolis - TO, Brasil. Professora do Programa de PósGraduação da Universidade Federal do Maranhão (UFMA), Imperatriz - MA, Brasil. E-mail: sousakarina@uft.edu.br

** Professora da Universidade Federal do Tocantins (UFT), Porto Nacional - TO, Brasil. E-mail: liza.bra@mail.uft.edu.br 


\section{Introdução}

O ideal projetado sobre uma sociedade que se reconheça e seja reconhecida enquanto democrática, mesmo que sob diferentes modelos, orienta-se no exercício da cidadania, em que estejam assegurados os direitos civis, políticos, sociais e culturais. Logo, a fragilidade na garantia desses direitos compromete o próprio fundamento de uma sociedade democrática. No Brasil, movimentos sociais, organizações não-governamentais e o poder público representam alguns dos agentes atuantes na implementação de políticas que procuram garantir a cidadania e os direitos humanos. Muitas dessas ações visam incluir indivíduos e grupos historicamente subalternizados a partir do reconhecimento e da valorização da diversidade. Contudo, a atuação do poder público tem, ao longo da história do país, persistido na manutenção de medidas que, quando não garantem, prorrogam o exercício pleno da cidadania para alguns grupos. Neste contexto, a organização da sociedade civil apresenta-se enquanto uma dimensão fundamental quanto às possibilidades de transformação social. Essa organização ocorre, em um número significativo de experiências, articulada a instituições públicas.

O Centro de Referência em Cidadania e Direitos Humanos (CRCDH), objeto central de análise deste artigo, representa um possível modelo de desenvolvimento de ações articuladas entre a sociedade civil e as instituições de ensino superior, em busca da garantia de acesso a direitos. Neste sentido, a análise de um programa de extensão voltado para a promoção dos direitos humanos e da cidadania em uma região com altos índices de desigualdade social orientou a reflexão sobre o acesso à cidadania por três grupos primordiais: mulheres, negros e indígenas. Este artigo pretende destacar uma das ações desenvolvidas no âmbito do CRCDH que teve como principais interlocutoras mulheres residentes no município de Tocantinópolis, localizado no extremo norte do estado do Tocantins. Dentre as ações desenvolvidas, este artigo destacará aquelas direcionadas à análise e ao combate da violência doméstica no espaço de agência do programa.

O CRCDH iniciou suas atividades no ano de 2013 na condição de projeto extensão. Neste período, o projeto foi coordenado pela então docente do curso de Licenciatura em Ciências Sociais do campus universitário de Tocantinópolis da Universidade Federal do Tocantins (UFT), prof ${ }^{a}$ dra. Liza Aparecida Brasílio. Em sua primeira fase, o projeto abrigou um grupo de estudos composto por estudantes e professores universitários, e realizou palestras, rodas de conversa e uma formação específica sobre a Lei Maria da Penha para agentes públicos e a comunidade local no município supracitado.

A proposta de expansão do projeto ocorreu a partir do ano de 2014, com a aprovação em um edital lançado pelo Ministério da Educação e Cultura e a Secretaria de Educação Superior desta pasta. Neste ano, outras linhas de ação e outros docentes somaram-se àquelas já desenvolvidas pela docente/coordenadora. Foram incorporadas as linhas relações étnicas e raciais, promoção da igualdade racial e educação para as relações étnico-raciais, sucessivamente coordenadas pelos docentes prof. dr. André Demarchi, prof. ms. Odilon Rodrigues e prof ${ }^{\mathrm{a}} \mathrm{ms}$. Karina Almeida de Sousa. 
Permanecendo sob coordenação da docente Liza Brasílio, o projeto concorreu ao edital do ano subsequente (2015-2016), sendo novamente contemplado, e desde modo mantendo e expandindo suas ações e linhas de atuação no período de 2013 a 2017 ${ }^{\mathrm{i}}$. Atualmente, o Programa não possui financiamento próprio e compartilha sua sede com o Laboratório de Mídias do curso de Licenciatura em Ciências Sociais. Além disso, mantém parte dos equipamentos ${ }^{\mathrm{ii}}$ adquiridos por meio dos editais.

Durante os anos de 2015 a 2016, as atividades do programa estruturaram-se em três eixos centrais: gênero e violência contra a mulher; relações étnicas e raciais e promoção da igualdade racial; planejamento urbano e rural. Foram implementados grupos de estudos de caráter formativo nas linhas temáticas, além de espaços de debate público, ações voltadas ao acesso à cidadania pelos grupos contemplados no edital e apresentação de dados em eventos para a comunidade.

$\mathrm{O} \mathrm{CRCDH}$ atuou como um espaço para acolhimento e encaminhamento diário de demandas da comunidade local, contemplando a orientação dos indivíduos no amplo espectro dos direitos humanos e da cidadania, e estabeleceu um intercâmbio e diálogo com a rede de serviços públicos, consolidados por meio de parcerias com diferentes órgãos e instituições municipais, estaduais e federais ${ }^{\text {iii }}$.

Bolsistas de extensão atuaram, de forma orientada, à frente das ações propostas pelo Centro. Os/as bolsistas desenvolviam atividades relacionadas ao atendimento ao público no âmbito interno e externo da universidade, ações em escolas municipais e estaduais, nas aldeias da etnia Apinajé e, ainda, em comunidades locais e organizações a serem atendidas 'in loco'. Essas atividades visaram o desenvolvimento social e o espírito crítico dos estudantes, por meio de ações pautadas na cidadania e na função social da educação superior. O contato direto com realidades concretas e saberes mostraram-se de fundamental importância para a intersecção entre pesquisa e extensão no ambiente universitário.

Conceber a extensão como atividade indissociável do processo educativo é traduzi-la nas atividades de ensino-aprendizagem, de estágio, de pesquisa, bem como nas atividades culturais que possibilitem o desenvolvimento de uma postura cidadã. A extensão aproxima academia e comunidade, contribuindo para a construção de uma cidadania ativa, compromissada com a realidade social. Nesse sentido, como um espaço orientado à promoção da cidadania, o CRCDH voltou-se à formação dos estudantes e a promoção de acesso a direitos aos indivíduos da microrregião do Bico do Papagaio ${ }^{\text {iv }}$.

O estado do Tocantins é o mais recente estado do território brasileiro. Circunscrito por intensas lutas pela terra entre fazendeiros, população indígena, quilombolas e movimento dos trabalhadores sem-terra, além de recente expansão do agronegócio ${ }^{v}$ e da instalação de projetos de geração de energia, o estado é marcado, ainda, por um dos piores indicadores socioeconômicos do país.

Até o ano de 1988, a unidade federativa, hoje conhecida como Tocantins, integrou a unidade de Goiás. Conhecida, então, como antigo norte-goiano, a atual microrregião do Bico 
do Papagaio possui sua sede política na capital, Palmas. Situado na região Norte, o estado possui, segundo o censo demográfico da população brasileira, realizado pelo Instituto Brasileiro de Geografia e Estatística (IBGE) no ano de 2010, 1.532.902 habitantes, sendo 222.548 na microrregião do Bico do Papagaio (IBGE, 2016).

Segundo dados apresentados por Oliveira e Strassburg (2014, p. 131),

\begin{abstract}
O universo da pobreza no estado vem desde a sua estrutura socioeconômica baseada na exploração da mineração no século XVIII até os dias atuais. Os últimos resultados do censo (IBGE, 2010) mostram que o Brasil tem 16,2 milhões de brasileiros que vivem em extrema pobreza, o equivalente a $8,5 \%$ da população. No Tocantins, esse percentual chega a $11,8 \%$ da sua população vivendo em extrema pobreza, são cerca de 163 mil de um total habitantes.
\end{abstract}

O CRCDH organizou-se como um espaço capacitado para realizar atividades de intermédio entre sociedade civil e Estado voltadas à constituição de espaços e dinâmicas que buscassem a garantia do exercício da cidadania e transformações dos IVS. A orientação dos indivíduos para que pudessem, em médio e longo prazo, obter conhecimento sobre seus direitos e reivindicá-los, contribuindo, desta forma, para uma sociedade mais justa, apresentou-se como foco central do programa. Nesse processo, pequenas ações puderam contribuir na construção da cidadania, pois "sonhar com cidadania plena em uma sociedade pobre, em que o acesso aos bens e serviços é restrito, seria utópico.” (PINSKY, 2003, p. 10).

\title{
A instalação do Centro de Referência em Cidadania e Direitos Humanos no Bico do Papagaio
}

Os Direitos Humanos estão previstos na Constituição Nacional e em Declarações Nacionais e Internacionais, portanto, no plano formal, uma gama de direitos individuais e coletivos estaria assegurada. A efetivação desses direitos, no entanto, não tem se concretizado tal como prevê o arcabouço jurídico. Boa parte da população permanece alijada dos direitos básicos, como saúde, educação, moradia, cultura, saneamento básico. Como garantir Direitos Humanos em uma sociedade excludente e desigual?

As políticas públicas e as ações das diversas instituições são fundamentais para a concretização dos direitos humanos. A partir desta concepção é que o CRCDH buscou atuar junto à comunidade acadêmica e à população do município e seu entorno. 
Figura 1 - Microrregião do Bico do Papagaio-Tocantins

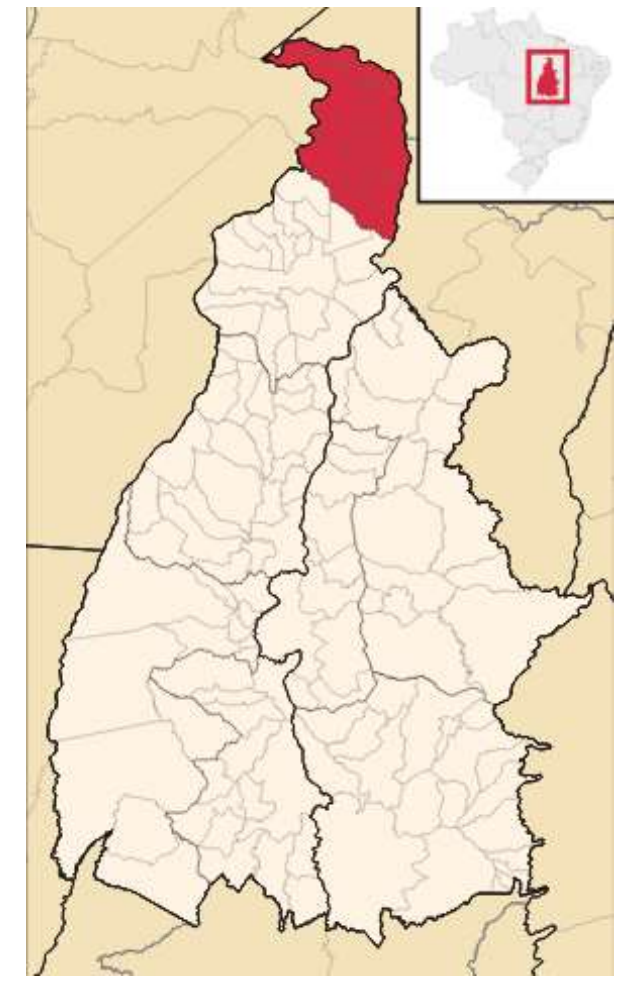

Fonte: IBGE, 2016

A microrregião conhecida como Bico do Papagaio está localizada no extremo norte do estado do Tocantins, estabelecendo fronteira geográfica com os estados do Maranhão, Bahia, Piauí e Pará e é composta por 25 municípios ${ }^{\mathrm{vi}}$. A região integrou o Norte Goiano ${ }^{\mathrm{vii}}$ até os anos de 1988 do século XX quando da formação do Estado do Tocantins. Sediou, ainda, um dos maiores movimentos revolucionários do país - A Guerrilha do Araguaia. Tocantinópolis possui cerca de sete aldeias indígenas e mais de $50 \%$ do seu território reconhecidamente demarcado e ocupado por indígenas da etnia Apinajé, além de uma população majoritariamente negra ${ }^{\text {viii }}$. Dentre as diversas abordagens que poderíamos construir sobre a região em que o programa foco desta reflexão foi implementado, custa-nos refletir sobre os dados que podem nos indicar as condições vulnerabilidade social dos municípios do Bico do Papagaio e, em especial, do município de Tocantinópolis.

A implementação e consequente análise das ações desenvolvidas por um programa no formato de um Centro de Referência em Cidadania e Direitos Humanos na região supracitada destaca-se à medida em que possamos observar o nível de vulnerabilidade social ao qual essa população está submetida. Por vulnerabilidade social tomamos o conceito formulado pelo Instituto de Pesquisa Aplicadas (IPEA). Segundo o IPEA (2015), o Índice de Vulnerabilidade Social (IVS) pretende expressar o acesso, a ausência ou a insuficiência de ativos em todas as 
áreas do território nacional. Esses ativos são tomados por direitos que deveriam estar garantidos pelo Estado a todo aquele cidadão e cidadã em território nacional. O IVS é composto por três subíndices: 1) infraestrutura urbana; 2) capital humano; e 3) renda e trabalho. Tomaremos, em nossa análise, pontos específicos dos subíndices, a fim de criar subsídios para o debate sobre cidadania e ausência de direitos na região.

A definição de vulnerabilidade social elaborado pelo IPEA nos indica que

diz respeito, precisamente, ao acesso, à ausência ou à insuficiência de ativos, constituindose, assim, num instrumento de identificação das falhas de oferta de bens e serviços públicos no território nacional. Nesta medida, este índice foi pensado para dialogar com o desenho da política social brasileira, uma vez que atesta a ausência ou insuficiência de "ativos" que, pela própria Constituição Federal de 1988 (CF/1988), deveriam ser providos aos cidadãos pelo Estado, nas suas diversas instâncias administrativas (INSTITUTO DE PESQUISA ECONÔMICA APLICADA, 2015).

Faremos uso dos dados disponíveis no Atlas da Vulnerabilidade Social, desenvolvido pelo IPEA no ano de 2015 (INSTITUTO DE PESQUISA ECONÔMICA APLICADA, 2015). O Atlas contribui com dados expressivos quanto às condições e acesso aos bens e serviços da população residente na microrregião analisada. Primeiramente, daremos enfoque aos índices de desenvolvimento humano. De acordo com os dados, apenas no subitem longevidade os municípios que integram o Bico do Papagaio atingem a média nacional $(0,816)$. No caso dos índices de renda e educação, esses dados são ainda mais díspares quando comparados à média nacional.

As taxas relativas ao número de analfabetos com 15 anos ou mais superam em todos os municípios, em mais de 100\%, a média nacional (9,61\%). Apenas nos municípios de Aguiarnópolis (17,15\%), Ananás (19,27\%), Angico (17,21\%), Araguatins (19,77\%), Cachoeirinha (18,2\%), Luzinópolis (18,19\%), Palmeiras do Tocantins (16,86\%), São Bento do Tocantins $(19,66 \%)$ e Tocantinópolis $(15,69 \%)$ os índices são inferiores a $20 \%$ de analfabetos. No entanto, nos municípios listados os índices variam no intervalo de 15,69\% (Tocantinópolis) a 19,77\% (Araguatins). (INSTITUTO DE PESQUISA ECONÔMICA APLICADA, 2015)

Esses dados nos permitem inferir que uma parcela significativa da população ocupada exerce cargos com baixa escolarização e, consequentemente, baixa remuneração. Essa inferência pode também ser verificada nas taxas da população com 18 anos de idade ou mais que não concluíram o ensino fundamental e exercem atividades informais. Mais uma vez, a microrregião supera em todos os municípios analisados a taxa média nacional $(35,24 \%)$. Os municípios com taxa inferior a 50\% são Aguiarnópolis (41,71\%), Ananás (47,25\%), Angico (48,34\%) e Tocantinópolis $(42,3 \%)$, e as maiores taxas encontram-se nos municípios de Darcinópolis $(61,73 \%)$, Esperantina (60,23\%), Itaguatins (62,15\%), Maurilândia do Tocantins (62,3\%), Praia Norte (61,59\%), Riachinho (63,54\%) e Sítio Novo do Tocantins (62,84\%). (INSTITUTO DE PESQUISA ECONÔMICA APLICADA, 2015)

As informações sobre o acesso ao saneamento básico e à rede de esgoto nos servem como indicadores não apenas do planejamento urbano e do impacto ambiental, mas, também, 
como indicativos das condições e acesso aos direitos básicos de saúde e bem-estar. Os dados apresentados no IVS da microrregião reiteram a vulnerabilidade social da região em todas os municípios do Bico do Papagaio. A taxa de domicílios com abastecimento de água e esgotamento sanitário inadequados são expressamente superiores à média nacional $(6,12 \%)$. No caso dos municípios de Praia Norte $(38,5 \%)$, São Bento do Tocantins $(38,76 \%)$ e Esperantina $(37,42 \%)$, as taxas superam $35 \%$ dos domicílios. Interessa-nos ainda observar que os dados da microrregião estudada refletem dados da região Norte. (INSTITUTO DE PESQUISA ECONÔMICA APLICADA, 2015)

Ao estabelecermos análises comparativas entre os índices da microrregião do Bico do Papagaio com os índices da Região Norte (INSTITUTO DE PESQUISA ECONÔMICA APLICADA, 2015), observamos um continuum no que se refere aos IVS, especialmente quanto à precariedade de políticas públicas habitacionais, educacionais, culturais e de saúde pública. Esse dado indica que a oferta regional de serviços de qualidade deva ser aquém do necessário para o atendimento aos direitos básicos da cidadania. Isso gera desde a necessidade de longos deslocamentos para o acesso a serviços até elevados índices de baixa escolarização e analfabetismo, além de um cenário pouco propício para transformações efetivas com vias ao acesso pleno aos direitos e ao exercício da cidadania.

De acordo com o Censo de 2010 (IBGE, 2010), o município de Tocantinópolis possui uma população de 22.608 pessoas. Essa população está distribuída em 6.201 domicílios. As informações apresentadas no Mapa da Fome dos Municípios Brasileiros (IPEA, 2003) dão indicativos sobre o quadro social do município. De acordo com essa fonte, $45,42 \%$ da população tocantinopolina se enquadra no padrão de renda definido como pobreza. A constatação referente ao ano de 2003 foi referendada e atualizada pelos dados da Secretaria Nacional de Renda e Cidadania do Ministério do Desenvolvimento Social - MDS no ano de 2017.

O contexto instabilidade política, social e econômica tem influído na redução do número de beneficiários das políticas públicas de assistência social e geração de renda, inclusive por circular, nas grandes mídias, reduções drásticas ${ }^{\mathrm{ix}}$ nos números de beneficiários de programas como o Bolsa Família. Ao multiplicarmos o número de famílias beneficiadas no ano de 2017, informado pela Secretaria Nacional de Renda e Cidadania do MDS, pelo número médio de habitantes por domicílio (IBGE, 2010), que para Tocantinópolis é de 3,8, chega-se a uma estimativa de que cerca de 8.648 habitantes possuíam, à época, algum grau de dependência dos recursos do Programa Bolsa Família. Esse dado representa 46,8\% de sua população total do município. Os dados apresentados acima, embora sucintos, indicam claramente que o município de Tocantinópolis abriga uma população caracterizada pela exclusão econômica, educacional, habitacional e de saúde.

Tal situação fomentou, nos gestores e nas instituições públicas localizadas na região, a necessidade de planejamento e execução de políticas públicas que promovam ações voltadas para a redução dos índices de pobreza, incentivo à geração de renda e à escolarização, principalmente no que toca a alfabetização de crianças e jovens e a qualificação de jovens e adultos, além do fomento à geração de emprego e renda, à produção e disseminação de cultura, à orga- 
nização e ao planejamento para a ocupação do espaço urbano e rural, o incentivo às pequenas propriedades rurais com fins produtivos, e o reconhecimento, valorização e disseminação das cultuas indígenas ${ }^{\mathrm{x}}$ e negras que constituem a microrregião do Bico do Papagaio. Esses seriam alguns dos principais eixos norteadores para os quais se fez urgente a execução de ações voltadas à ampliação dos direitos políticos, civis, sociais e culturais na região.

O Plano Nacional de Desenvolvimento Humano (PNDH-3) propunha, em seu documento, o fortalecimento da democracia, pensada como igualdade econômica e social. Este documento ressaltava, ainda, a importância dos setores organizados "para exigir a efetivação de relações sociais igualitárias e justas." (BRASIL, 2010, p. 5). A universidade deve também contribuir com a garantia dos direitos humanos e propiciar reflexões e ações voltadas para a temática, bem como produzir e socializar conhecimento, implementando uma efetiva relação entre academia e sociedade.

A Universidade Federal do Tocantins $(2010)^{\mathrm{xi}}$, conforme constou em seu Plano de Desenvolvimento Institucional referente ao período de implementação do CDHC (2011-2015), teve, como parte de sua missão, a articulação com a sociedade no que se refere às relações com órgãos públicos, com a sociedade civil e com instituições privadas, no intuito de promover ações voltadas à inclusão social com respeito à pluralidade e à diversidade.

O contexto socioeconômico descrito, somado à existência de uma instituição de educação de nível superior na região, alicerçou um espaço para pesquisas que indicaram a necessidade de instalação de um espaço capaz de articular as demandas da sociedade civil e contribuir para o fortalecimento da cidadania e autonomia em conjunto com demais instituições sociais promotoras de direitos.

A meta destacada no Centro foi o desenvolvimento de um Programa que se relacionasse com a investigação científica e com a produção de conhecimentos voltados à qualificação do ensino, a partir da realidade sociocultural, em consonância com a comunidade da região onde ele atuaria. $\mathrm{O}$ objetivo geral do $\mathrm{CRCDH}$ foi a disseminação de informações no âmbito dos Direitos Humanos e da Cidadania na chave da diversidade, de forma a propiciar aos indivíduos conhecimentos referentes aos seus direitos, aos espaços de execução dos direitos e, ainda, aos suportes jurídicos, médicos e educacionais, na medida em que cada linha de ação desenvolvia suas atividades.

De modo abrangente, como desdobramento de um objetivo central, o CRCDH desenvolveu atividades com foco em geração de autonomia; promoção da cidadania; mediação entre os indivíduos e as instituições jurídicas para a garantia dos direitos; promoção e formação de agentes públicos e populares oriundos da sociedade civil organizada; e incentivo a atividades de pesquisa no âmbito do ensino superior público. 


\section{Direitos humanos, cidadania e diversidade}

Os direitos humanos e a cidadania, em consonância com o respeito e reconhecimento à diversidade, são aspectos essenciais para uma sociedade democrática. Não há possibilidade de democracia sem que sejam assegurados os direitos dos cidadãos e os direitos humanos.

A compreensão da cidadania, em sua leitura clássica, foi elaborada por Marshall, na obra Cidadania e Classe Social (1979), calcada nos pilares do iluminismo, e condenou a diferenciação ou desigualdade qualitativa entre os homens, cunhada pelo status social. Como alternativa, o autor elabora a cidadania como parâmetro de igualdade. Neste sentido, a igualdade básica se embasaria na associação com a participação integral na comunidade, ou seja, com o exercício pleno dos direitos contidos na noção de cidadania. A cidadania transfere, então, a esfera do direito local ao universal, ampliando direitos a todos os homens.

Segundo Marshall (1979), o desenvolvimento da cidadania até o fim do século XIX proporcionou a compreensão dos direitos civis, políticos e sociais. Uma apresentação cronológica do conceito indica a seguinte estrutura: no século XVIII, se deu a emergência dos direitos civis, os quais trataram da liberdade individual (liberdade de ir e vir, imprensa, pensamento e fé, propriedade e justiça). Emergiram, ainda, os direitos políticos, ou seja, os direitos de participar do exercício do poder político, os quais dialogam com o sufrágio universal, transferindo sua base do substrato econômico ao status pessoal.

Surgidos no século XIX, os direitos sociais serão, já no século XX, associados aos direitos civis e políticos na composição da cidadania. No século XX, a participação de comunidades e associações irá pautar a incorporação desses direitos à noção de cidadania. A cidadania passa, então, a ser pensada como um status concedido àqueles que são membros integrais de uma comunidade.

A concepção de cidadania regulada desenvolvida por Santos (1979) se funda como desdobramento da concepção de cidadania formulada por Marshall (1979). Este modelo teria como pressuposto a formação do cidadão por meio do reconhecimento e capacitação para a inserção no mundo do trabalho. Santos $(1979$, p. 74$)$ insere a cidadania enquanto pertinente à passagem da esfera da acumulação para esfera da equidade, que é compreendida por meio da ocupação no mercado de trabalho, ou seja, esse é o parâmetro utilizado pelo autor para definir a igualdade entre os sujeitos. De acordo com Santos (1979, p.75),

são cidadãos todos aqueles membros da comunidade que se encontram localizados em qualquer uma das ocupações reconhecidas e definidas em lei. Neste sentido, a expansão da cidadania pode se dar pela regulamentação de novas profissões e/ou ocupações, e mediante a ampliação do escopo de direitos associados a estas profissões, antes que por meio dos valores inerentes aos conceitos de membro da comunidade. 
O conceito de cidadania regulada (SANTOS, 1979) define a incorporação dos direitos, já elaborados por Marshall (1979), aos indivíduos necessariamente imersos nos parâmetros do reconhecimento profissional ou ocupacional. Essa perspectiva irá se opor às demandas emergentes em meados do século XX, já que, a partir dessa data, retornam ao cenário social um número significativo de movimentos sociais, nomeados posteriormente como "novos movimentos sociais ${ }^{\mathrm{xii}}$ ". Os grupos que incorporam o que se nomeou como novos movimentos sociais serão articulados por categorias distintas das anteriormente utilizadas.

De acordo com Pinsky (2003, p. 9), a cidadania está circunscrita aos direitos à vida, à liberdade, à propriedade, à igualdade, ou seja, aos direitos civis. $\mathrm{O}$ autor destaca ainda como marcos da cidadania a participação nos processos decisórios da sociedade, votar e ser votado, esses abrigados na esfera dos direitos políticos. Logo, nas palavras do autor, "Os direitos civis e políticos não asseguram a democracia sem os direitos sociais, aqueles que garantem a participação do indivíduo na riqueza coletiva: o direito à educação, ao trabalho, ao salário justo, à saúde, a uma velhice tranquila." (PINSKY, 2003, p. 9).

Segundo Bobbio (1992 apud ÁVILA, 2002, p. 124), “direitos humanos significam, na sua origem, uma passagem do dever do súdito para o direito do cidadão". O autor define como marco dessa conquista as Declarações de Direitos dos Estados Norte-Americanos e da Revolução Francesa, nascendo aí as bases de uma nova concepção de Estado. A Declaração Universal de Direitos Humanos de 1948 define outra fase, "na qual a afirmação dos direitos é, ao mesmo tempo, universal e positiva."

Ávila (2002) observa que a definição de Direitos Humanos vem sendo ampliada para todos os campos da vida social: "nesse sentido, os Direitos Humanos são reivindicados, hoje, como referência nas lutas por políticas emancipatórias e são definidos como questão central para o desenvolvimento da cidadania e da democracia." (ÁVILA, 2002, p. 124).

Se durante grande parte do século XX o debate e a ação dos movimentos sociais estiveram atrelados às demandas no campo das lutas trabalhistas - paridade salarial, redução de jornadas, férias e aumentos salariais - as demandas e ações dos principais movimentos estiveram majoritariamente voltadas para o combate às desigualdades de classe. Nesse novo plano, as demandas apresentam-se de modo menos integrado, ou melhor, descentradas da categoria classe. Serão as experiências vivenciadas a partir de raça, etnia, gênero, sexualidade, territorialidade, religiosidade, elementos que tomam a cena pública e o debate acadêmico. (Re)emergem aqui movimentos organizados a partir de suas dimensões identitárias, como, por exemplo, o Movimento Negro e o Movimento de Gays, Lésbicas, Travestis e Transexuais.

De acordo com Ávila (2002), a cidadania ganhou destaque no Brasil a partir de sua referência aos projetos de transformação social, nesse sentido a luta pela democracia estaria atrelada à luta por uma cidadania efetiva e real. Contudo, a inexistência ou fragilidade da cidadania indica a permeabilidade dos valores democráticos e, consequentemente, o desrespeito aos direitos humanos (ÁVILA, 2002, p. 125). 
Desta forma, cidadania tem sido tema de debates políticos, pauta dos movimentos sociais, das organizações não governamentais, entre outros. Ao se difundir pela sociedade, passa a ser também incorporada pelos sujeitos sociais, que buscam, mesmo individualmente, seus direitos. Na esfera da busca por direitos individuais, acentuamos que os direitos dos cidadãos dizem respeito ao

domínio sobre seu corpo e sua vida, o acesso a um salário condizente para promover a própria vida, o direito à educação, à saúde, à habitação, ao lazer. E mais: é direito de todos poder expressar-se livremente, militar em partidos políticos e sindicatos, fomentar movimentos sociais, lutar por seus valores. Enfim, o direito de ter uma vida digna de ser homem (COVRE, 2007, p. 9).

Como garantir a cidadania, os direitos e deveres em uma sociedade excludente, desigual, na qual boa parte da população não tem acesso aos bens básicos de sobrevivência? Esta situação de exclusão faz com que parte da população e de grupos estejam alijados de seus direitos e, assim, não exerçam sua cidadania, tornando-se necessárias ações que visem à promoção da cidadania, para que os grupos e sujeitos possam, a médio e longo prazo, ter conhecimento dos seus direitos e, assim, reivindicá-los, contribuindo para uma sociedade menos desigual. Isto é, ações de todas as dimensões podem contribuir na construção da cidadania, pois

sonhar com cidadania plena em uma sociedade pobre, em que o acesso aos bens e serviços é restrito, seria utópico. Contudo os avanços da cidadania se têm a ver com a riqueza do país e a própria divisão de riquezas depende também da luta e das reivindicações, da ação concreta dos indivíduos [...] (PINSKY, 2003, p. 13).

\section{Gênero e violência contra a mulher}

As demandas que partiram do descentramento da categoria trabalho, em razão da emergência e visibilidade de outras categorias descritivas, foram socialmente construídas no espaço da marginalidade e direcionadas às posições sociais subalternas. Esses grupos são, majoritariamente, compostos por jovens universitários: grupos marginalizados, uma nova classe trabalhadora, mulheres, negros/as, gays, lésbicas, travestis e transexuais. Serão esses os principais atores que irão compor os Novos Movimentos Sociais (NMS).

Desde o começo argumentávamos que a política, ao tratar principalmente de partidos políticos formais, eleições, incitando ao voto, ao parlamentarismo, era ideológica, constrangedora. Levamos questões da vida pessoal, o jeito das pessoas viverem, cultura que não se consideravam tópicos políticos de esquerda. Queríamos falar sobre este novo tipo de sociedade capitalista na qual as pessoas não tinham uma linguagem para exprimir suas dificuldades, não percebiam que estas dificuldades refletiam questões políticas e sociais que poderiam ser vistos desde um ponto de vista geral. (FRASER apud ADELMAN, 2009, p. 43). 
O cenário de emergência das diversas posições de sujeito e de uma espécie de polifonia de vozes somou definições do ambiente acadêmico direcionadas à emergência de atores sociais, ao grau de modificação na sociedade e cultura ocidental e à relação entre a vida privada e a ação coletiva. Acreditando na transformação cultural, na importância dos novos atores sociais e da ação destes últimos nas esferas da vida social, a vida privada e a vida cultural estavam na arena política e o movimento de mulheres que mostrou que a vida privada é mais do que nunca coisa pública.

Neste sentido, vale ressaltar o lembrete dado por Hall (2006, p. 400),

não existia um "novo movimento social" naquela época. Para nós, isso não representava uma nova fase (ou forma) da política. Achávamos que se trata ainda do velho jogo político, que conduzíamos de uma nova maneira. Somente quando olhamos para trás é que percebemos que a Nova Esquerda foi uma primeira antecipação da era dos "novos movimentos sociais".

Partes das disputas do feminismo se firmaram sob o paradigma da revolução sexual em detrimento aos modelos que pautaram uma revolução feminina, segundo a qual as mulheres ainda continuariam ocupando o espaço privado em oposição à figura do homem. Este, socialmente compreendido a partir do domínio do espaço público, e aquelas, ainda compreendidas na esfera da obrigação sexual dentro dos espaços privados aos quais seriam direcionadas. $\mathrm{O}$ discurso, a partir dos movimentos que se organizaram em torno deste novo feminismo, como demonstra Adelman (2009, p. 62), pautaram a politização do gênero e da sexualidade, impulsionados pela nova esquerda e pela contracultura.

O CRCDH desenvolveu suas atividades centrado nas linhas de ação apresentadas no primeiro tópico deste artigo. A partir daqui nos pautaremos nas atividades direcionadas ao debate das relações de gênero e do combate à violência contra a mulher. Partimos da compreensão de gênero como construto social que se dá a partir das relações e símbolos que circulam na sociedade contemporânea, nesse sentido, gênero não será, nesta reflexão, tratado como sinônimo de sexo biológico.

Pesquisas, seminários, manifestações da sociedade civil têm contribuído com o avanço do arcabouço teórico e legal que criminaliza a violência doméstica no Brasil. A Lei $\mathrm{n}^{\mathrm{o}}$ 11.340, conhecida como Lei Maria da Penha, foi criada em 7 de agosto de 2006 (BRASIL, 2006), com o intuito de qualificar e tipificar a violência doméstica cometida contra mulheres em quaisquer tipos de relações afetivas. Desde a sua criação, a violência contra a mulher passou a incorporar cinco tipos específicos de ação violenta: a violência patrimonial, a violência psicológica, a violência moral, a violência física, a violência sexual.

De acordo com as disposições gerais da Lei Maria da Penha (BRASIL, 2006), configura violência doméstica e familiar contra a mulher qualquer ação ou omissão baseada no gênero que lhe cause morte, lesão, sofrimento físico, sexual ou psicológico e dano moral ou patrimonial. A lei rege relações de convívio permanente entre as pessoas, sejam ou não do 
círculo familiar, ou em qualquer relação íntima de afeto, na qual o agressor conviva ou tenha convivido com a vítima. Ainda em suas disposições, o texto afirma a violência contra a mulher como uma das violações dos direitos humanos.

O Estado do Tocantins tem apresentado índices alarmantes de violência contra a mulher. De acordo com os dados publicados pela titular da Delegacia de Atendimento à Mulher do Centro-Norte, o estado do Tocantins, no ano de 2016, ocupou o segundo lugar no ranking dos estados com maiores taxas de violência cometida contra mulheres. Segundo a Delegacia Especializada no Atendimento à Mulher (DEAM) do Centro-Norte, a capital do estado, Palmas, foi considerada a primeira no ranking entre as capitais com maior índice de violência contra a mulher no país. Dados do Mapa da Violência- Homicídios de Mulheres no Brasil, publicado pela Faculdade Latino-Americana de Ciências Sociais (FLACSO, 2015), indicam que a taxa de homicídios de mulheres a cada 100 mil é de 5,7\% ocupando a $13^{a}$ colocação, enquanto a capital, Palmas, apresenta a maior taxa de crescimento de homicídios de mulheres e ocupa a $6^{\mathrm{a}}$ posição entre as capitais $(9,5 \%)$.

A violência contra a mulher, marcada por uma lógica masculinista de poder e sua associação à legitimidade da violência, estrutura-se nos mais diferentes âmbitos da vida social. É sabido ainda que a violência contra a mulher não se restringe a critérios de classe ou cor/raça, mesmo que mulheres negras e/ou pobres constem como maiores vítimas da violência. Quando observamos mais atentamente o perfil étnico e racial e os dados sobre vulnerabilidade social da Região Norte, de modo geral, e especificamente do Bico do Papagaio, podemos compreender parcialmente os altos índices de violência apresentados pelo estado do Tocantins.

Destacamos que, no Brasil, as mulheres negras (pretas e pardas) são as maiores vítimas de violência doméstica. Especificamente no que toca aos dados sobre vulnerabilidade social das mulheres no Bico do Papagaio, podemos observar altas taxas de gravidez na adolescência e de mulheres chefes de família com baixa escolarização.

Dentre as inúmeras atividades promovidas pelo $\mathrm{CRCDH}$, duas receberão destaque nesta reflexão. A primeira marca o que, de acordo com os dados encontrados até o momento, seria uma primeira pesquisa, de cunho quantitativo, sobre violência doméstica no município de Tocantinópolis. Foram aplicados 70 questionários, com o objetivo de mapear o perfil das mulheres residentes no município de Tocantinópolis e suas experiências relacionadas à violência de gênero.

A segunda atividade foi a elaboração de uma rede de atendimento às mulheres vítimas de violência, que envolveu agentes, instituições púbicas e a sociedade civil. As pesquisas e atividades foram circunscritas ao município onde o programa atua, no entanto, ao observarmos regularidades entre os municípios circunvizinhos, tais como número similar de habitantes, número similar de domicílios, proximidade de renda e condições de inserção no mercado de trabalho, além dos índices de escolarização, podemos tomar o caso analisado como um caso exemplar para a região. Seguem alguns dados que nos permitem realizar tal aproximação.

No dia 6 de março de 2015, foi realizado um evento em comemoração ao Dia Internacional da Mulher pela então Secretaria de Mulheres, atrelada à Prefeitura do Município de 
Tocantinópolis. Na ocasião, foi realizada uma parceria entre a Secretaria e o CRCDH. Estudantes ${ }^{x i i i}$ participantes do programa aplicaram um questionário desenvolvido pela equipe de coordenação, com o objetivo de mapear questões específicas sobre a violência contra a mulher.

Setenta mulheres foram entrevistadas. Entre o grupo, havia entrevistadas domiciliadas nas regiões urbanas e rurais, sendo que a amostra foi definida aleatoriamente a partir do convite das estudantes (entrevistadoras) e o aceite das participantes do evento (entrevistadas). Entre as entrevistadas, uma maioria expressiva é alfabetizada, considerando-se desde o ensino fundamental incompleto até o ensino superior completo. Um número significativo de mulheres se autodeclarou parda (49), amarela (3), branca (5), e negras (13). Ainda entre as entrevistadas, 30 se apresentaram à época da entrevista como solteiras, 19 casadas, 2 divorciadas, 14 viviam em união estável e 5 eram viúvas.

Quanto à renda familiar, observou-se que $70 \%$ das entrevistadas viviam com até um salário-mínimo ${ }^{\text {xiv }}$, ou seja, 54 respondentes; outras 13 viviam com renda entre 2 e 4 saláriosmínimos, e 3 responderam que viviam na faixa de 5 a 8 salários-mínimos. No que diz respeito à renda familiar, mais de $70 \%$ das famílias compostas pelas entrevistadas viviam com renda mínima de até 1 salário-mínimo. Segundo a pesquisa, apenas 9 mulheres não possuíam filhos; 17 possuíam entre um 1 e 2 filhos; 12 entre 3 e 4; e 8 entre 5 e 10 filhos. Ainda, 24 entrevistadas não responderam a essa questão.

No questionário utilizado, desenharam-se técnicas mistas que englobaram questões fechadas (de múltipla escolha) e questões abertas. As questões direcionadas ao tema específico da violência contra a mulher buscaram atender a dois objetivos específicos: 1) expressar um ordenamento social acerca dos padrões de gênero e como eles influem nas relações afetivasconjugais; 2) mapear o conhecimento das entrevistas sobre a Lei Maria da Penha e as estruturas básicas de atendimento à mulher vítima de violência doméstica.

A partir de expressões de uso cotidiano, buscamos acessar a reflexão das entrevistadas sobre a violência contra a mulher praticada em âmbito doméstico. A questão "Em briga de marido e mulher ninguém mete a colher" dividiu opiniões, expressando um desacordo significativo entre as entrevistadas. Mais de 50\% das entrevistadas discordaram da afirmação; aproximadamente $58 \%$ das mulheres que responderam não, enquanto $49 \%$ responderam afirmativamente.

Observamos que a porcentagem de mulheres que se opôs à expressão foi numericamente superior, no entanto, a porcentagem de mulheres que compreende a violência doméstica como algo do campo do privado foi bastante expressivo. O construto social que aloca as mulheres no âmbito do espaço e das relações privadas, em oposição ao homem enquanto ocupante dos espaços e de relações públicas, contribui para a perpetuação da violência contra a mulher, já que, nesta concepção, as relações privadas passam afastadas da dimensão política. Essa, por sua vez, deveria estar restrita ao espaço público, o que poderia acabar reforçando uma dinâmica da agressão como restrita ao âmbito privado e, consequentemente, tendendo a naturalização da violência doméstica tanto pelo agressor quanto pela agredida. 
As mulheres que responderam se opondo à afirmação deram indícios de que, nos casos de agressão, têm buscado auxílio nos mais diversos espaços. A experiência de implementação do CRCDH corrobora este dado, visto que, durante sua atividade com atendimento e orientação às vítimas de violência doméstica, mesmo que com baixa divulgação no município de modo geral, o CRDCH acompanhou e orientou diversos casos.

O divórcio foi apresentado como alternativas para o fim da violência. Nesse caso, 91,3\% das entrevistadas acreditam que a separação seria a melhor opção para uma mulher que sofreu violência do parceiro. Existe, ainda, uma percepção social de que a violência atinja ou se concentre em populações de baixa renda, e tal percepção não se difere quando refletimos sobre a violência doméstica, mas ancora-se no imaginário violento construído para as famílias de classes baixas (imaginário constantemente explorado e reproduzido por grandes mídias e o Estado). Na presente pesquisa, mais de $50 \%$ das entrevistadas dizem acreditar que a violência contra a mulher ocorre majoritariamente nas classes sociais baixas.

$\mathrm{O}$ acesso aos aparatos jurídicos foi explorado a partir da apreensão sobre o arquivamento de processo de violência contra a mulher. Mesmo com os critérios jurídicos para retirada da denúncia ${ }^{\mathrm{xv}}$, inúmeras estratégias podem ser utilizadas a fim de incentivar $\mathrm{o}$ arquivamento dos processos, desde a negativa do fato até o abrandamento dos relatos sobre a violência. Essas são algumas das formas adotadas pelas vítimas. No caso do questionário, as entrevistadas discordam majoritariamente de tais estratégias: $75 \%$ das entrevistadas acreditam que a falta de colaboração nos processos seria uma forma de descrédito ao aparato público de justiça. Para as respondentes, a atitude indica que a mulher necessita garantir o andamento do processo para que seu agressor seja responsabilizado, já que se trata da manutenção de sua segurança.

A reprodução de um padrão de comportamento de gênero pode ser claramente constatada no questionamento sobre a naturalidade da agressividade masculina. Mais de $80 \%$ das entrevistadas afirmaram que o homem tem tendência a ser mais agressivo que a mulher.

O segundo objetivo do questionário, que era mapear o conhecimento das entrevistadas sobre a Lei Maria da Penha, apresentou resultados bastante promissores. Mais de $90 \%$ das entrevistadas afirmam conhecer a Lei. Esses dados demonstram também o sucesso de difusão da Lei Maria da Penha na sociedade brasileira.

Quando questionadas sobre as instituições às quais deveriam recorrer para realizar denúncias referentes à violência contra a mulher, os dados indicam questões positivas quanto à disseminação de informações sobre a Lei. Foram listadas diversas instituições, dentre as quais as entrevistadas deveriam indicar aquelas que seriam especializadas no atendimento, acolhimento e acompanhamento de denúncias de violência contra a mulher. A lista continha as seguintes instituições: Receita Federal, Delegacia Especializada no Atendimento à Mulher, PROCON, Defensoria Pública, Instituto Natureza do Tocantins (Naturatins), Ministério Público, Assistência Social, Delegacia Civil, Centro de Referência em Cidadania e Direitos Humanos, Fórum, Secretaria da Mulher do Município de Tocantinópolis ou, ainda, nenhum dos órgãos listados. 
Mais de 50\% das mulheres indicaram a Delegacia Especializada no Atendimento à Mulher como espaço para acolhimento das denúncias de violência doméstica, totalizando 21 respondentes; houve uma frequência considerável de respostas que indicavam instituições com funções aproximadas como, por exemplo, a Secretaria da Mulher, a Defensoria Pública e a Assistência Social do município. Um número reduzido indicou espaços como o PROCON e o Instituto Natureza do Tocantins (Naturatins).

Diante da grande variedade de respostas, há indícios de que existe uma compressão, de âmbito mais geral, de que órgãos ligados ao sistema judiciário, assim como demais instituições públicas (CRCDH), possuem competência para acompanhar e orientar os casos de violência.

Mesmo reconhecendo dificuldades em publicizar a violência em localidades com número reduzido de habitantes, em que se garantir o anonimato dos parceiros, das entrevistadas e entrevistadoras é um desafio, optamos por manter uma questão específica sobre violência doméstica. Aproximadamente $35 \%$ das entrevistadas afirmaram nunca ter sofrido nenhum tipo de violência, ao passo que $27 \%$ negaram-se a responder à questão. Esse dado mostra o engodo que a publicização da violência doméstica enfrenta, especialmente em espaços onde as relações são marcadas por um modelo de sociabilidade mais comunitário do que societário.

Nessas espacialidades, as denúncias de violência contra a mulher e como elas podem ser acentuadas por contextos externos compõem análises a serem realizadas. Tais contextos referem-se às dinâmicas de cidades com poucos habitantes, em que toda a comunidade estabelece uma convivência próxima e que as distinções entre público e privado são entrecruzadas; e, ainda, como a violência publicizada pode ser compreendida pelo grupo, gerando outra forma de exclusão de mulheres perante seu grupo e suas relações sociais.

As demandas trazidas pela aplicação do questionário contribuíram, conjuntamente, com as parcerias realizadas pelo CRCDH e a Secretaria da Mulher do município de Tocantinópolis para a participação deste centro na Conferência Municipal e na Conferência Estadual de Mulheres. Posteriormente a essas participações, intensificaram-se as demandas pela abertura de um espaço permanente no Conselho Municipal da Mulher para o CRDH e para a FUNAI ${ }^{\mathrm{xvi}}$. Este cenário contribui, ainda, para uma terceira dimensão das atividades desenvolvidas pelo programa: a proposição, organização e coordenação de uma Rede de Atendimento às Mulheres Vítimas de Violência Doméstica.

A Rede de Atendimento às Mulheres Vítimas de Violência Doméstica foi inicialmente planejada pelo CRCDH, em conjunto com a Secretaria da Mulher de Tocantinópolis. Atuaram, neste primeiro momento, estudantes e docentes vinculados ao Programa, a secretária da mulher e duas assistentes que atuavam na mesma Secretaria. Diversas reuniões foram realizadas, com o objetivo de se elaborar um termo de cooperação entre as instâncias diretamente relacionadas ao acolhimento, encaminhamento e acompanhamento das mulheres vítimas de violência doméstica.

As reuniões contaram com a participação de uma ampla gama de agentes da sociedade civil e dos órgãos municipais, estaduais e federais. Participaram os seguintes órgãos: Defensoria Pública, Ministério Público, Polícia Militar, Polícia Civil, Secretaria da Mulher 
de Tocantinópolis, Secretaria de Saúde de Tocantinópolis, Secretaria de Administração de Tocantinópolis, CREAS, CRAS, Instituto Médico Legal, Ordem dos Advogados do Brasil, Delegacia especializada no atendimento à mulher da comarca de Tocantinópolis.

Um complexo relatório sobre o papel desempenhado por cada uma das instituições nos casos de violência doméstica foi elaborado pelo CRCDH. No relatório, para além das atividades já realizadas, foram apresentados dados sobre as possíveis contribuições de cada instituição e as demandas relacionadas à capacidade de atendimento. Os dados foram apresentados e discutidos em uma série de reuniões no auditório do Ministério Público e na UFT. Após esses encontros, elaboraram-se estratégias, a fim de se estabelecerem parâmetros de comunicação e acompanhamento dos casos pelas instituições componentes da rede. Um termo de compromisso também foi elaborado. A este termo seguiria anexo um protocolo detalhado de atendimento.

Destaca-se que a participação efetiva e o manifesto interesse dos diversos órgãos do poder público garantiram a viabilidade do projeto e seu encaminhamento. Caberia, então, ao CRDH, como instância vinculada à UFT e à sociedade civil, realizar a mediação e o acompanhamento da rede e de seus parceiros, com vistas a preparar materiais de divulgação e esclarecimento, além de intermediar a relação entre os diversos órgãos componentes da rede. Por fim, o projeto encontra-se em suspenso devido à suspensão da Secretaria da Mulher no município de Tocantinópolis e a definição de uma nova coordenação junto ao CRCDH.

Para Covre (2007, p.10),

direitos e deveres (conteúdo do exercício de cidadania) é algo possível, mas dependente do enfrentamento político adotado por quem tem pouco poder. Só existe cidadania se houver a prática da reivindicação, da apropriação de espaços, da pugna para fazer valer os direitos do cidadão.

Neste sentido, a prática da cidadania pode ser a estratégia, por excelência, para a construção de uma sociedade com menores índices de desigualdade de gênero, racial, étnica, geracional e territorial. O primeiro pressuposto dessa prática seria a garantia ao direito de reivindicar os direitos, e o acesso irrestrito ao conhecimento pela população.

\section{Referências}

ADELMAN, M. A voz e a escuta: Encontros e desencontros entre a teoria feminista e a socilogia contemporânea. São Paulo: Edgard Blucher, 2009.

APPIAH, K. A. Cultura, comunidade e cidadania. São Paulo: Ática, 1999. 
ÁVILA, Maria Betânia. Cidadania, direitos humanos e direitos das mulheres. In: BRUSCHINI, Cristina; UNBEHAUM, Sandra. Gênero, democracia e sociedade brasileira. São Paulo: Editora 34, 2002.

BHABHA, H. K. O local da cultura. Tradução de Myrian Ávila, Eliana Lourenço de Lima Reis e Gláucia Renate Gonçalvez. Belo Horizonte: Editora UFMG, 2007.

BRASIL. Lei $\mathrm{N}^{\mathrm{o}} 11.340$, de 7 de agosto de 2006. Cria mecanismos para coibir a violência doméstica e familiar contra a mulher, nos termos do $\S 8^{\circ}$ do art. 226 da Constituição Federal, da Convenção sobre a Eliminação de Todas as Formas de Discriminação contra as Mulheres e [...]; e dá outras providências. Diário Oficial da União, Brasília, DF, 8 ago. 2006. Disponível em: http://www.planalto.gov.br/ccivil_03/_ato2004-2006/2006/lei/111340.htm. Acesso em: 23 set. 2020.

BRASIL. Decreto $\mathrm{n}^{\circ}$ 8.381, de 29 de dezembro de 2014. Regulamenta a Lei $\mathrm{N}^{\circ} 12.382$, de 25 de fevereiro de 2011, que dispõe sobre o valor do salário-mínimo e a sua política de valorização de longo prazo. Diário Oficial da União, Brasília, DF, 29 dez. 2014. Disponível em: http://www.planalto.gov.br/ccivil 03/ ato2011-2014/2014/decreto/d8381.htm Acesso em: 02 de agosto de 2020.

BRASIL. Secretaria de Direitos Humanos da Presidência da República. PNDH - 3 Programa Nacional de Direitos Humanos. Brasília: SDH/PR, 2010.

COVRE, Maria de Lourdes Manzini. O que é cidadania. São Paulo: Brasiliense, 2007.

EMPRESA BRASILEIRA DE PESQUISA AGROPECUÁRIA- EMBRAPA, 2021.

Matopiba. Disponível em: https://www.embrapa.br/tema-matopiba/sobre-o-tema. Acesso em: 3 maio 2021.

FACULDADE LATINO-AMERICANA DE CIÊNCIAS SOCIAIS-FLACSO. Mapa da Violência- Homicídios de Mulheres no Brasil, 2015. Disponível em: https://flacso.org.br/?p=13485. Acesso em 02 de agosto de 2021.

HALL, Stuart. A centralidade da Cultura: notas sobre as revoluções culturais do nosso tempo. Educação \& Realidade, Porto Alegre, v. 22, n. 2, p. 15-46, jul./dez. 1997.

HALL, Stuart. A Identidade Cultural na Pós-Modernidade. Tradução de Tomaz Tadeu da Silva e Guacira Lopes Louro. Rio de Janeiro: DP\&A, 2005.

HALL, Stuart. Stuart Hall por Stuart Hall. Uma entrevista com Stuart Hall, de Kuan- Hsing Chen. In: HALL, Stuart. Da Diáspora: Identidade e Mediações Culturais. Belo Horizonte. Editora UFMG, 2006. 
IBGE. Instituto Brasileiro de Geografia e Estatística. Censo Demográfico. 2016. Disponível em: https://www.ibge.gov.br/busca.html?searchword=censo+demogr\%C3\%A1fico. Acesso em: 23 set. 2020.

IBGE. Instituto Brasileiro de Geografia e Estatística. Mapa da Pobreza e Desigualdade Brasília: IPEA, 2003. Disponível em: https://cidades.ibge.gov.br/brasil/pesquisa/36/30252. Acesso em: 02 de agosto de 2021.

INSTITUTO DE PESQUISA ECONÔMICA APLICADA. Atlas da vulnerabilidade social nos municípios brasileiros. Brasília: IPEA, 2015. Disponível em: http://ivs.ipea.gov.br/ images/publicacoes/Ivs/publicacao_atlas_ivs.pdf. Acesso em: 12 dez. 2020.

MADEIRO, Carlos. Com redução de 543 mil bebefícios em 1 mês, Bolsa Família tem maior corte da história. Uol Cotidiano, 2017. Disponível em https://noticias.uol.com.br/ cotidiano/ultimas-noticias/2017/08/11/bolsa-familia-reduz-543-mil-beneficios-em-1-mesprograma-tem-maior-corte-da-historia.htm. Acesso em 15 de agosto de 2017.

MARSHALL, T. H. Cidadania e classe social. In: Cidadania, classe social e status. Rio de Janeiro: Zahar Editores, 1979.

OLIVEIRA, Nilton Marques; STRASSBURG, Nilton. Notas sobre a desigualdade social no Bico do Papagaio - Tocantins. Desafios: Revista Interdisciplinar da Universidade Federal do Tocantins, v. 1, n. 1, p. 130-148, jul./dez. 2014. Disponível em: https://sistemas.uft.edu.br/periodicos/index.php/desafios/article/view/772/128-145. Acesso em: 12 dez. 2020.

PINSKY, Jaime. Introdução. In: PINSKY, Jaime; BASSANEZI, Carla Pinsky (orgs.). História da cidadania. São Paulo; Contexto, 2003.

PINTO, Célia Regina. Teoria política feminista, desigualdade social e democracia no Brasil. In: BRUSCHINI, Cristina; UNBEHAUM, Sandra. Gênero, democracia e sociedade brasileira. São Paulo: Editora 34, 2002.

POVOS INDÍGENAS NO BRASIL. Apinajé. Disponível em: https://pib.socioambiental.org/pt/ povo/apinaye/62. Acesso em: 12 dez. 2020.SANTOS, W. G. A política social na ordem brasileira. Rio de Janeiro: Editora Campus Ltda., 1979.

SADER, Emir (org.). Vozes do Século. Entrevistas da New Left Review. Rio de Janeiro: Paz e Terra. 1997.

SILVÉRIO, V. R. Evolução e contexto atual das políticas públicas no Brasil: educação, desigualdade e reconhecimento. In: HERINGER, R.; MARILENE, P. Caminhos convergentes: Estado e sociedade na superação das desigualdades raciais no Brasil. Rio de Janeiro: Fundação Herinch Boll \& Action Aid, 2009. p. 13-38. 
TORRES, C. A. Democracia, educação e multiculturalismo: dilemas da cidadania no mundo globalizado. In: TORRES, C. A. (org.). Teoria Crítica e Sociologia Política da Educação. São Paulo: Cortez, 2003. p. 63-101.

UNIVERSIDADE FEDERAL DE TOCANTINS. História da UFT. Disponível em: https://ww2.uft.edu.br/index.php/acessoainformacao/institucional/historia. Acesso em: 23 set. 2020.

UNIVERSIDADE FEDERAL DO TOCANTINS. Conselho de Ensino, Pesquisa e Extensão - CONSEPE. Projeto Político Pedagógico do Curso de Ciências Sociais. Universidade Federal do Tocantins, Campus de Tocantinópolis, 2006.

UNIVERSIDADE FEDERAL DO TOCANTINS. PDI - Plano de Desenvolvimento Institucional da Universidade Federal do Tocantins, 2011-2015. Palmas: UFT, 2010. Disponível em: https://docs.uft.edu.br/share/proxy/alfresco-noauth/api/internal/shared/ node/uiLXT5kyRMS0xcbKcAc7cw/content/PDI\%202011-2015.pdf. Acesso em: 12 dez. 2020.

\footnotetext{
Notas

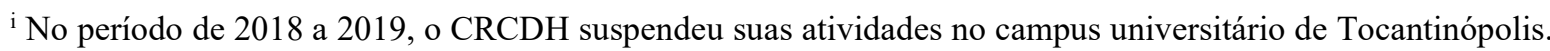
O Centro está em fase de reorganização e constituição da equipe docente e discente.

ii Durante a vigência dos dois editais aos quais o $\mathrm{CRCDH}$ foi contemplado, foram adquiridos equipamentos como câmeras fotográficas, máquinas filmadoras, computadores [ilhas de edição], kits multimídias, microfones e lousas digitais. O edital permitiu, ainda, a publicação do livro Direitos Humanos e Diversidades (2018). Parte desses equipamentos foi doada ao campus sede do projeto e os demais compõem o acervo atual do Centro.

iii Durante os anos de 2013 a 2016, o CRCDH estabeleceu parcerias com alguns órgãos públicos municipais, estaduais e federais. São eles: escolas da rede pública municipal e estadual localizadas no município de Tocantinópolis, Secretaria da Mulher do Município de Tocantinópolis, Ministério Público, Defensoria Pública, Política Civil e Militar, Prefeitura do município de Tocantinópolis, por meio das Secretarias de Administração, Educação, Saúde e Assistência Social, Fundação Nacional do Índio (FUNAI), Instituto Médico Legal (IML), Ordem dos Advogados do Brasil (OAB).

iv Embora o Bico do Papagaio denomine a área do Interflúvio Araguaia-Tocantins, localizada na porção setentrional do território tocantinense, ela compreende ainda o sudoeste do Maranhão até o sudeste do Pará, a que a denominação Bico do Papagaio comumente se reporta (OLIVEIRA; STRASSBURG, 2014, p. 130). Neste estudo, a análise recai apenas sobre a Microrregião do Tocantins, especificamente sobre o município de Tocantinópolis, onde o $\mathrm{CRCDH}$ foi instalado.

v O Matopiba é uma região formada pelo estado do Tocantins e partes dos estados do Maranhão, Piauí e Bahia, onde ocorreu forte expansão agrícola a partir da segunda metade dos anos 1980, especialmente no cultivo de
} 
grãos. O nome é um acrônimo formado pelas siglas dos quatro estados (MARANHÃO + TOCANTINS + PIAUÍ + BAHIA) (EMBRAPA, 2021).

${ }^{v i}$ Constitui a microrregião do Bico do Papagaio os municípios de: Axixá do Tocantins, Nazaré, Riachinho, Sampaio, Sítio Novo do Tocantins, Aguiarnópolis, Ananás, Angico, Araguatins, Augustinópolis, Buriti do Tocantins, Cachoeirinha, Carrasco Bonito, Darcinópolis, Esperantina, Itaguatins, Luzinópolis, Maurilândia do Tocantins, Palmeiras do Tocantins, Praia Norte, Santa Terezinha do Tocantins, São Bento do Tocantins, São Miguel do Tocantins, São Sebastião do Tocantins e Tocantinópolis. Todos são localizados no estado do Tocantins (IBGE, 2016).

vii Constitui a microrregião do Bico do Papagaio os municípios de: Axixá do Tocantins, Nazaré, Riachinho, Sampaio, Sítio Novo do Tocantins, Aguiarnópolis, Ananás, Angico, Araguatins, Augustinópolis, Buriti do Tocantins, Cachoeirinha, Carrasco Bonito, Darcinópolis, Esperantina, Itaguatins, Luzinópolis, Maurilândia do Tocantins, Palmeiras do Tocantins, Praia Norte, Santa Terezinha do Tocantins, São Bento do Tocantins, São Miguel do Tocantins, São Sebastião do Tocantins e Tocantinópolis. Todos são localizados no estado do Tocantins (IBGE, 2016).

viii Segundo Mapa da Distribuição Espacial da População, Segundo a Cor ou Raça - Pretos e Pardos - Brasil, publicado pelo IBGE em 2010, o estado do Tocantins possui $72,2 \%$ de seus habitantes autodeclarados pretos ou pardos. Esse número distribui-se da seguinte forma: 9,1\% pretos e 63,1\% pardos (IBGE, 2016).

${ }^{i x}$ No mês de agosto de 2017, o Programa Bolsa Família sofreu a maior redução do número de beneficiários desde seu início. Cerca de 540 mil beneficiários tiveram seus benefícios suspensos (MADEIRO, 2017).

${ }^{x}$ Os Apinajé pertencem ao tronco Macro-Jê, família Jê descendentes do grupo Timbira e vivem numa área demarcada, a partir de 1985, de 141.904 hectares, próximos aos municípios de Tocantinópolis, Maurilândia e Lagoa de São Bento. Sua população atual é de 2.277 (Siasi/Sesai, 2014), distribuídos em 7 aldeias (POVOS INDÍGENAS NO BRASIL, 2020).

${ }^{x i}$ A Universidade Federal do Tocantins (UFT) foi instituída em 23 de outubro de 2000 pela Lei ${ }^{\circ} 10.032$, a partir da transferência dos cursos e da infraestrutura da Universidade do Tocantins (Unitins), mantida pelo Estado do Tocantins. Embora tenha sido criada no ano 2000, a UFT só teve sua implantação efetiva em maio de 2003, com a posse dos primeiros professores da Instituição. (UNIVERSIDADE FEDERAL DO TOCANTINS, 2010)

xii A década de 60 do século XX pode ser conceituada a partir das novas formas de expressão política e da emergência dos novos movimentos sociais (NMS). Ambos se relacionam com as transformações dos processos de identificação e das relações sociais cotidianas por meio do estabelecimento de novas formas de organização coletivas. Esses grupos seriam, majoritariamente, compostos por jovens universitários, negros, mulheres, e a nova classe trabalhadora.

xiii Contribuíram com a elaboração do questionário bolsistas vinculadas ao CRCDH e a técnica da Secretaria da Mulher à época, Cristine Rosa. Contribuíram com as análises dos questionários os seguintes bolsistas vinculados ao CRCDH: Elisabete Marques Henriques dos Santos; Gasparina Ferreira Lima de Souza; Wesley da Silva Sousa; Willian da Silva Sousa e Williansmar da Silva Sousa.

xiv $O$ Decreto no 8.381 de 2014 institui o valor do salário-mínimo para o ano de 2015 em R $\$ 788,00$.

${ }^{\mathrm{xv}}$ Após alterações, a Lei prevê que a retirada da denúncia poderá ser efetiva apenas após o cumprimento de uma audiência específica para a situação. Essa alteração se ocorreu considerando as diversas situações em que mulher, vítima da violência doméstica, buscava suspender a denúncia seja em situação de coesão por parte do agressor, ou mesmo, outras situações específicas. Conforme prevê o Art. 16 da Lei Maria da Penha, "Nas ações penais públicas condicionadas à representação da ofendida de que trata esta Lei, só será admitida a renúncia à representação perante o juiz, em audiência especialmente designada com tal finalidade, antes do recebimento da denúncia e ouvido o Ministério Público". (BRASIL, 2006).

xvi Na ocasião da Conferência Municipal da Mulher a geógrafa e técnica da Funai, Patrícia Moojen Lemos, participou dos debates, contribuindo, no tema da violência doméstica sofrida pelas mulheres da etnia Apinajé. 